\title{
HUBUNGAN ANTARA DERAJAT OSTEOARTRITIS DENGAN GAMBARAN USG TULANG RAWAN PADA PASIEN OSTEOARTRITIS LUTUT DI RSU AL FAUZAN PERIODE TAHUN 2016-2017
}

\author{
Riza Amalia ${ }^{1}$, Basuki Supartono ${ }^{2}$, Ika Satya ${ }^{3}$, Sugeng Wiyono ${ }^{4}$ \\ ${ }^{1}$ Program Studi Sarjana Kedokteran, FK UPN “Veteran” Jakarta \\ 2Departemen Bedah Ortopedi, FK UPN "Veteran" Jakarta \\ ${ }^{3}$ Departemen Farmakologi, FK UPN "Veteran" Jakarta \\ ${ }^{4}$ Research Program, FK UPN "Veteran" Jakarta \\ Email: rizaamalia6695@gmail.com
}

\begin{abstract}
Background: Osteoarthritis is a degenerative joint disease which is related with the damage of cartilage. X-Ray is one of the osteoarthritis radiological examinations but only to see the damage of bone not cartilage. One of an effective examination to visualize the damage of cartilage is Ultrasound.

Method: The objective of this study is to determine the relation between osteoarthritis grading scale with cartilage ultrasonographic in knee osteoarthritis patients. This was a Cross-sectional study on 32 knee osteoarthritis patients based on Total Sampling technique at RSU Al Fauzan period of 2016-2017. Statistical analysis was performed using Fisher test showed there was a correlation between osteoarthritis grading scale with cartilage ultrasonographic.
\end{abstract}

Result: The most distribution of patients based on age was middle age (45-59) which was 46.9\%, the most distribution of patients based on sex was female at $71.9 \%$, the distribution of OA degrees based on the Kellgren and Lawrence scale, the most was grade III at 59.4\%

Conclusion: The conclusion in this study, there is a significant correlation between osteoarthritis grading scale with cartilage ultrasonographic in knee osteoarthritis patients.

Keywords: Knee Osteoarthritis, Ultrasound, X-Ray

\section{ABSTRAK}

Pendahuluan: Osteoartritis (OA) merupakan penyakit sendi degeneratif yang dihubungkan dengan kerusakan tulang rawan sendi. X-Ray adalah salah satu pemeriksaan radiologi OA tapi hanya untuk melihat kerusakan dari tulang bukan tulang rawan. Salah satu pemeriksaan efektif yang dapat memvisualisasikan kerusakan tulang rawan adalah Ultrasonografi (USG). Tujuan penelitian ini adalah untuk mengetahui hubungan antara derajat osteoartritis dengan gambaran USG tulang rawan pada pasien osteoartritis lutut.

Metode: Penelitian ini menggunakan desain potong lintang dengan jumlah sampel 32 pasien yang diambil dengan teknik Total Sampling di RSU AI Fauzan tahun 2016-2017. Analisis statitik menggunakan uji Fisher menunjukkan terdapat hubungan antara derajat osteoartritis dengan gambaran USG tulang rawan.

Hasil: distribusi pasien berdasarkan usia yang terbanyak adalah Usia Pertengahan (45-59) yaitu sebesar 46.9\%, distribusi pasien berdasarkan jenis kelamin yang terbanyak adalah perempuan sebesar $71.9 \%$, distribusi derajat OA berdasarkan skala Kellgren dan Lawrence yang terbanyak adalah derajat III sebesar $59.4 \%$

Kesimpulan: Kesimpulan penelitian ini adalah terdapat hubungan antara derajat osteoartritis dengan gambaran USG tulang rawan pada pasien osteoartritis lutut.

Kata kunci:Osteoartritis Lutut, USG, X-Ray 


\section{PENDAHULUAN}

Osteoartritis (OA) adalah penyakit degeneratif yang disebabkan oleh kerusakan tulang rawan sendi ${ }^{1}$. Osteoartritis biasanya mengenai sendi penopang berat badan misalnya pada lutut, panggul, vertebra, tetapi dapat juga mengenai bahu, sendi-sendi jari tangan, dan pergelangan kaki².

Prevalensi OA di Indonesia mencapai $15,5 \%$ pada pria dan $12,7 \%$ pada wanita. Menurut World Health Organization (WHO), prevalensi penderita OA di dunia tahun 2004 mencapai 151,4 juta jiwa dan 27,4 juta jiwa berada di Asia Tenggara ${ }^{3}$. Menurut Soenarto ${ }^{4}$, pada usia $\geq 15$ tahun rata-rata prevalensi penyakit sendi/rematik sebesar 24,7\%. Propinsi Nusa Tenggara Timur merupakan propinsi dengan prevalensi OA tertinggi yaitu sekitar $33,1 \%$ dan propinsi dangan prevalensi terendah adalah Riau yaitu sekitar 9\% sedangkan DKI Jakarta menempati urutan keempat prevalensi OA sebesar $21,8 \%{ }^{5}$.

Tulang rawan sendi lutut merupakan lapisan rawan hialin setebal $5 \mathrm{~mm}$ yang melapisi tulang serta melaksanakan fungsi dan kebutuhan pergerakan sendi. Tulang rawan tersebut tidak mempunyai pembuluh darah, saraf, limfatik dan perikondrium. Nutrisi berlangsung secara difusi dengan metabolism sel rendah, terbatas dan bersifat anaerobic. Struktur dan fungsi tersebut menyebabkan rendahnya kemampuan penyembuhan sehingga menghasilkan jaringan parut ${ }^{6}$.

Berdasarkan $\mathrm{WHO}$, diagnosis $\mathrm{OA}$ dapat ditegakkan dengan pemeriksaan fisik dan juga pemeriksaan penunjang yaitu, artroskopi, MRI dan X-Ray. Sampai saat ini, pemeriksaan bagian dalam sendi (Artroskopi) masih menjadi pemeriksaan baku emas (goald standar) dalam mendiagnosis penyakit OA.
Salah satu pemeriksaan radiologis dalam mendiagnosis OA adalah X-Ray. Pemeriksaan $X$-Ray dapat melihat kerusakan tulang tetapi tidak dengan tulang rawan. Gambaran OA dalam pemeriksaan radiologis $\mathrm{X}$-ray diklasifikasikan menurut Kellgren dan Lawrence dan dikelompokkan menjadi lima derajat (0-4). Gambaran tersebut dapat berupa osteofit, penyempitan celah sendi, dan sklerosis ${ }^{6}$.

Dalam salah satu literatur disebutkan bahwa pemeriksaan yang dapat menjadi alternatif dalam mendiagnosis OA lutut adalah ultrasonografi (USG) ${ }^{7}$. Pemeriksaan USG mempunyai beberapa kelebihan yaitu dapat mendeteksi osteofit, degenerasi tulang rawan, dan menjadi acuan dalam injeksi sendi yang tidak dapat ditentukan oleh pemeriksaan lain? ${ }^{7}$. Penelitian Jonathan K. Kazam, dkk, di Rumah Sakit Universitas Thomas Jefferson, mengakatan bahwa USG dapat menjadi pemeriksaan rutin untuk mendeteksi abnormalitas pada tulang rawan ${ }^{8}$.

Selama ini klasifikasi OA hanya didasarkan pada pemeriksaan X-Ray saja, sedangkan X-Ray adalah pencitraan untuk melihat tulang bukan jaringan. Oleh karena itu, peneliti ingin melakukan penelitian terhadap hubungan antara derajat $O A$ dengan gambaran USG tulang rawan pada pasien OA lutut.

Hasil penelitian ini diharapkan dapat menjadi tambahan informasi bagi dunia kedokteran khususnya dalam bidang ortopedi sehingga dapat menjadi alternatif untuk diagnosis dan juga pemeriksaan penunjang $O A$ lutut.

\section{METODE PENELITIAN}

Jenis penelitian yang digunakan adalah analitik observasional dengan desain penelitian cross-sectional. Penelitian dilakukan 
untuk mengetahui hubungan antara derajat $O A$ dengan gambaran USG tulang rawan pada pasien OA lutut di RSU Al Fauzan Periode Tahun 2016-2017.

Populasi yang digunakan pada penelitian ini adalah semua pasien yang terdiagnosis OA lutut yang memenuhi kriteria di Rumah Sakit Umum Al Fauzan periode tahun 2016 sampai 2017.

Sampel dalam penelitian adalah pasien yang telah terdiagnosis OA lutut primer di Rumah Sakit Umum Al Fauzan yang memenuhi kriteria sebanyak 32 sampel dalam periode tahun 2016 sampai 2017.

Kriteria inklusi penelitian ini adalah terdiagnosis $\mathrm{OA}$ lutut, mempunyai hasil pemeriksaan lutut dengan X-Ray, mempunyai hasil pemeriksaan lutut dengan USG dan usia minimal 25 tahun

Penelitian ini melakukan pengambilan sampel dengan menggunakan metode Non Probability Sampling dengan teknik sampel jenuh atau total sampling, yaitu peneliti memilih responden berdasarkan pada pertimbangan subyektif dan praktis 9 .
Jenis data yang dikumpulkan dalam penelitian ini adalah data sekunder, yaitu data yang didapatkan dari rekam medis pasien $O A$ lutut. Data yang dikumpulkan akan diverifikasi dan dimasukkan ke dalam basis data yang selanjutnya dianalisis.

Prosedur Penelitian

Data sekunder yaitu data yang sudah ada dirumah sakit berupa rekam medis. Data yang diambil berupa hasil pemeriksaan X-Ray dan pemeriksaan USG tulang rawan pada pasien OA lutut di Rumah Sakit Umum Al Fauzan.

\section{HASIL DAN PEMBAHASAN}

\section{Analisis Univariat}

Analisis ini dilakukan untuk melihat gambaran distribusi frekuensi karakteristik responden dan variabel - variabel yang diteliti. Analisis univariat yang dilakukan meliputi distribusi usia, jenis kelamin dan derajat $O A$ pada pasien OA lutut di RSU AI Fauzan.

\section{Tabel 1. Distribusi Pasien Berdasarkan Usia}

\begin{tabular}{lll}
\hline USIA & $\mathbf{N}$ & $\mathbf{( \% )}$ \\
\hline Dewasa (27-44) & 12 & 37.5 \\
\hline Usia Pertengahan (45-59) & 15 & 46.9 \\
\hline Lansia (>60) & 5 & 15.6 \\
\hline
\end{tabular}

Sumber : Rekam Medis RSU AI Fauzan

Berdasarkan tabel, didapatkan hasil bahwa responden dengan kelompok dengan usia terbanyak adalah
Usia Pertengahan (45-59) yaitu sebanyak 15 orang atau $46.9 \%$.

Tabel 2. Distribusi Pasien Berdasarkan Jenis Kelamin

\begin{tabular}{ccc}
\hline JENIS KELAMIN & N & (\%) \\
\hline Laki-laki & 9 & 28.1 \\
\hline Perempuan & 23 & 71.9 \\
\hline Sumber : Rekam Medis RSU Al Fauzan
\end{tabular}


Berdasarkan tabel, didapatkan jumlah responden dengan jenis kelamin terbanyak adalah perempuan sebanyak 23 orang atau $71.9 \%$.

Tabel 3. Distribusi Derajat Osteoartritis Berdasarkan Skala Kellgren dan Lawrence

\begin{tabular}{ccc}
\hline $\begin{array}{c}\text { HASIL } \\
\text { X-RAY }\end{array}$ & N & (\%) \\
\hline Derajat I & 0 & 0 \\
\hline Derajat II & 7 & 21.9 \\
\hline Derajat III & 19 & 59.4 \\
\hline Derajat IV & 6 & 18.8 \\
\hline
\end{tabular}

Sumber : Rekam Medis RSU Al Fauzan

Berdasarkan tabel, didapatkan jumlah sampel yang memiliki derajat OA terbanyak adalah derajat III sebanyak 19 orang atau $59.4 \%$.

\section{Pembahasan Analisis Univariat}

Distribusi frekuensi berdasarkan kelompok usia tertinggi diperoleh kelompok Usia Pertengahan (45-59 tahun) sebanyak 15 orang atau $46.9 \%$. Distribusi terendah diperoleh kelompok usia Lansia (>60 tahun) sebanyak 5 orang atau $15.6 \%$. Hasil ini sesuai dengan penelitian Heidari ${ }^{10}$ yang menyatakan dalam penelitiannya kelompok yang tertinggi adalah pasien berumur 55 tahun. Proses penuaan merupakan salah satu risiko utama yang dapat mengakibatkan sendi-sendi tubuh terutama sendi lutut mengalami peradangan atau pembengkakan yang bersifat progresif seiring bertambahnya umur. Proses penuaan dalam berbagai penelitian disebutkan dimulai dari umur 40-45 tahun bergantung pada kondisi kesehatan individu.

Distribusi jenis kelamin pada penelitian ini yang tertinggi adalah kelompok perempuan dengan persentase sebesar $71.9 \%$ atau 23 responden. Osteoartritis pada perempuan menurut literatur belum dapat dijelaskan secara ilmiah. Hal ini sejalan dengan penelitian
Mutiwara $^{11}$ yang menyatakan sebesar $75 \%$ kejadi OA banyak terjadi pada perempuan dibandingkan laki-laki. Dalam penelitian Hame $^{12}$, kemungkinan terdapat beberapa faktor yang dapat menjadi alasan meningkatnya risiko OA pada perempuan antara lain perbedaan anatomi, trauma dan genetik serta hormon. Perbedaan anatomi pada laki-laki dan perempuan yang dapat mendukung $\mathrm{OA}$ adalah femur yang sempit, patella yang tipis, sudut paha depan yang lebih besar dan perbedaan ukuran condylar tibialis. Walaupun semua hal yang telah disebutkan dapat terjadi, tapi belum ada penelitian yang dapat membuktikan bahwa semua itu berhubungan dengan peningkatan kejadian OA.

Pada penelitian ini, distribusi pasien OA berdasarkan derajat kerusakan $O A$ lutut Kellgren dan Lawrence yang terbanyak adalah derajat III dan distribusi terendah terdapat pada pasien dengan derajat II. Pada penelitian Mutiwara ${ }^{11}$ yang terdiagnosis OA lutut derajat III merupakan kelompok terbanyak dari semua pembagian derajat $O A$ lutut Kellgren dan Lawrence.

\section{Analisis Bivariat}

Berdasarkan tabel analisis hubungan antara derajat osteoartritis dengan gambaran 
USG tulang rawan pada pasien OA lutut diatas menunjukkan bahwa pasien yang memiliki skor USG 1-2 sebanyak 7 pasien dan untuk skor USG 3-4 ada sebanyak 25 pasien.

Analisis bivariat yang digunakan untuk mengetahui hubungan antara derajat osteoartritis dengan gambaran USG tulang rawan pada pasien OA lutut adalah uji ChiSquare, karena tidak memenuhi syarat dilanjutkan dengan uji alternatif yaitu uji Fisher. Berdasarkan hasil uji statistik Fisher dapat disimpulkan terdapat hubungan bermakna atau signifikan antara derajat $O A$ dengan gambaran USG tulang rawan pada pasien OA lutut dengan $p$ value $<0.05$.

Tabel 4. Hubungan Derajat Osteoartritis dengan Gambaran USG Tulang Rawan

Pada Pasien OA Lutut

\begin{tabular}{|c|c|c|c|c|c|c|c|}
\hline \multirow{3}{*}{$\begin{array}{l}\text { HASIL } \\
\text { USG }\end{array}$} & \multicolumn{4}{|c|}{ HASIL X-RAY } & \multirow{2}{*}{\multicolumn{2}{|c|}{ TOTAL }} & \multirow{3}{*}{$\begin{array}{l}P \\
\text { value }\end{array}$} \\
\hline & \multicolumn{2}{|c|}{$\begin{array}{l}\text { Skor } \\
1-2\end{array}$} & \multicolumn{2}{|c|}{ Skor 3-4 } & & & \\
\hline & $\mathbf{N}$ & $(\%)$ & $\mathbf{N}$ & $(\%)$ & $\mathbf{N}$ & (\%) & \\
\hline Derajat I & 0 & 0 & 0 & 0 & 0 & 0 & \multirow{5}{*}{0.000} \\
\hline Derajat II & 7 & 21.9 & 0 & 0 & 7 & 21.9 & \\
\hline Derajat III & 0 & 0 & 19 & 59.4 & 19 & 59.4 & \\
\hline Derajat IV & 0 & 0 & 6 & 18.8 & 6 & 18.8 & \\
\hline TOTAL & 7 & 21.9 & 25 & 78.1 & 32 & 100 & \\
\hline
\end{tabular}

Sumber : Rekam Medis RSU Al Fauzan

\section{Pembahasan Analisis Bivariat}

Penelitian ini menggunakan uji ChiSquare pada awalnya tetapi karena tidak memenuhi syarat maka dilanjutkan dengan uji alternatif yaitu uji Fisher. Dalam uji Fisher didapatkan $p$ value sebesar 0.000 atau $p$ value kurang dari 0.05 yang berarti terdapat hubungan antara derajat $O A$ dengan gambaran USG tulang rawan pada pasien OA lutut. Hasil penelitian Kazam $^{8}$ menunjukkan bahwa USG dapat menjadi pemeriksaan rutin untuk mendeteksi abnormalitas pada tulang rawan. Menurut penelitian Mortada ${ }^{7}$ USG bermanfaat dalam menilai keparahan dari OA lutut dengan hasil terdapat keakuran yang baik yaitu sensitifitas sebesar $94.6 \%$ dan spesitifitas sebesar $93.3 \%$.

Skala Kellgren dan Lawrence adalah skala kerusakan tulang rawan sendi lutut yang dilihat melalui pemeriksaan X-Ray dan terbagi kedalam lima derajat (0-IV) dengan menilai gambaran penyempitan celah sendi yang asimetris, peningkatan densitas tulang subkondral, kista tulang, osteofit pada pinggir sendi dan perubahan anatomi sendi dapat ditemukan pada saat pemeriksaan radiologi. Pemeriksaan X-Ray dapat melihat kerusakan tulang tetapi tidak dapat memvisualisasikan abnormalitas dari tulang rawan

Dalam salah satu literatur disebutkan bahwa pemeriksaan yang dapat menjadi alternatif dalam mendiagnosis OA lutut adalah ultrasonografi (USG) ${ }^{6}$. Hal tersebut didukung oleh penelitian Jonathan K. Kazam ${ }^{8}$, dkk, di Rumah Sakit Universitas Thomas Jefferson yang mengakatan bahwa USG dapat menjadi pemeriksaan rutin untuk mendeteksi abnormalitas pada tulang rawan.

Pada USG, kartilago artikular hialin normal memiliki penampilan anechoic atau homogen hypoechoic yang terdefinisi dengan baik dengan ketebalan yang seragam. Tahap awal OA dapat digambarkan dengan munculnya kesan seperti hilangnya kontur dan 
adanya gambaran tulang rawan yang bervariasi. Dalam tahap lanjut, tulang rawan menyempit secara asimetris, diikuti oleh kelainan di tulang subkondral ${ }^{8}$. Penelitian Grassi $^{13}$, dkk, melaporkan spektrum kelainan pada pasien dengan $\mathrm{OA}$, termasuk hilangnya ketajaman antarmuka antara tulang rawan dan ruang sinovial, hilangnya kejelasan kartilago dan penyempitan tulang rawan.

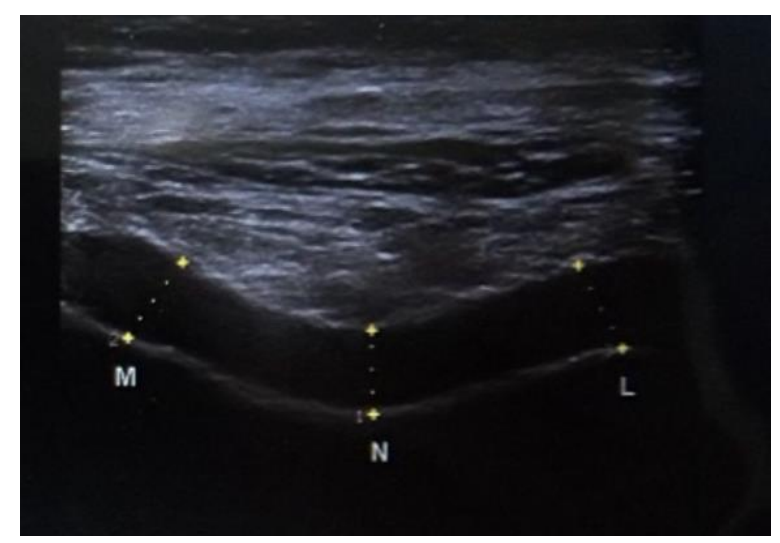

Sumber : Rekam Medis RSU Al Fauzan

Gambar 1. Gambaran USG tulang rawan normal

Penelitian ini menggunakan skala "Basuki" untuk mendeteksi atau menilai tulang rawan melalui USG dengan melihat adanya ketidakrataan permukaan tulang rawan, jarak celah sendi, kesuraman celah sendi dan defek tulang rawan. Dari 32 pasien yang diteliti, terdapat 7 pasien derajat II dengan skor USG 2 dimana gambaran USG tulang rawannya adalah celah sendi yang suram dan terdapat ketidakrataan pada permukaan tulang rawannya. Pasien derajat III dengan skor USG
3 sebanyak 19 pasien dengan gambaran USG tulang rawannya terdapat celah sendi yang suram, ketidakrataan pada permukaan tulang rawannya dan celah sendi yang menyempit. Sedangkan 6 pasien lainnya mendapatkan hasil derajat IV dengan skor USG 4 yaitu terdapat celah sendi yang suram, ketidakrataan pada permukaan tulang rawan, celah sendi yang menyempit dan adanya defek tulang rawan.

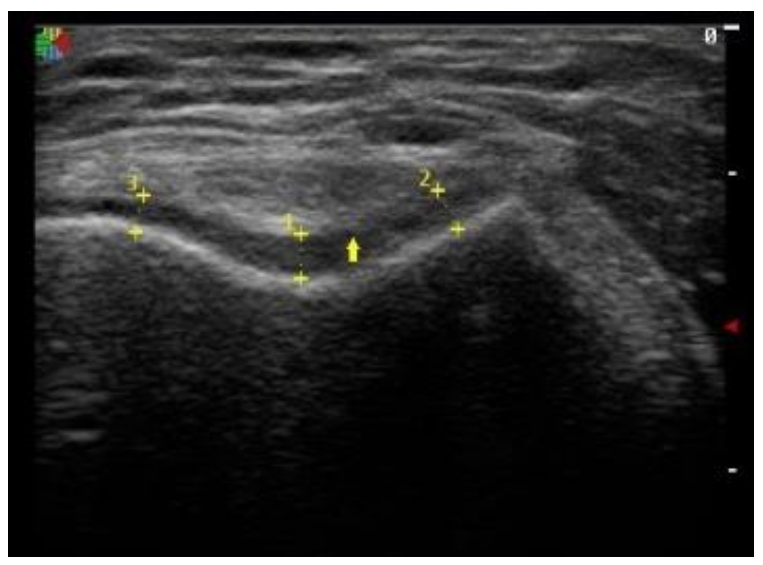

Sumber : Rekam Medis RSU Al Fauzan

Gambar 7. Derajat II (dengan KL) hasil: celah sendi suram dan permukaan tulang rawan tidak rata/irreguler 


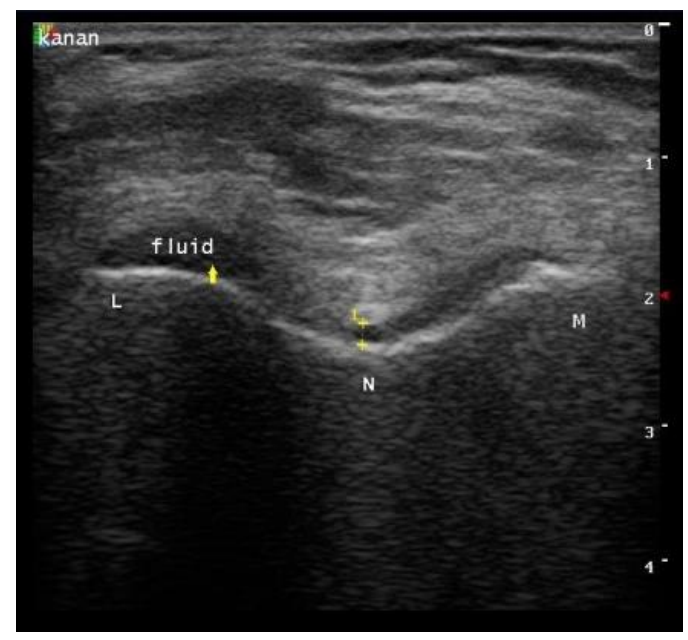

Sumber : Rekam Medis RSU Al Fauzan

Gambar 8. Derajat III (dengan KL), hasil: celah sendi suram, permukaan tulang rawan tidak rata/irreguler, celah sendi menyempit

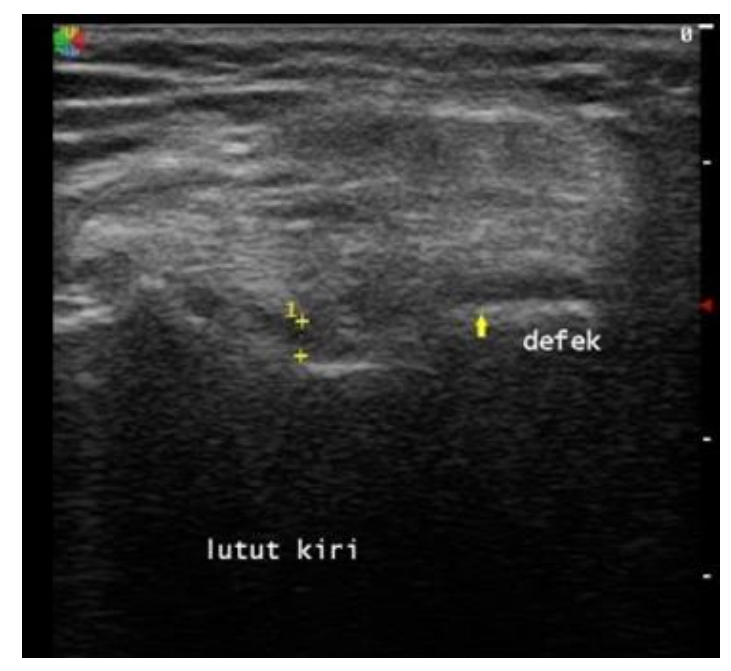

Sumber : Rekam Medis RSU Al Fauzan

Gambar 9. Derajat IV (dengan KL), hasil: celah sendi suram, permukaan tulang rawan tidak rata/irreguler, celah sendi menyempit, defek tulang rawan

Secara singkat, penelitian ini distribusi pasien berdasarkan usia yang menunjukkan adanya hubungan antara derajat terbanyak adalah Usia Pertengahan (45-59) OA menggunakan Kellgren dan Lawrence yaitu sebesar $46.9 \%$, distribusi pasien dengan gambaran USG tulang rawan pada berdasarkan jenis kelamin yang terbanyak pasien OA lutut $(p<0.05)$ dan juga pemeriksaan adalah perempuan sebesar $71.9 \%$, distribusi USG diharapkan dapat menjadi pertimbangan untuk digunakan sebagai salah satu alternatif pemeriksaan OA lutut.

\section{KESIMPULAN} derajat $\mathrm{OA}$ berdasarkan skala Kellgren dan Lawrence yang terbanyak adalah derajat III sebesar $59.4 \%$ dan terdapat hubungan signifikan antara derajat $O A$ dengan gambaran USG tulang rawan pada pasien OA lutut.

Berdasarkan hasil penelitian dan pembahasan, dapat ditarik kesimpulan 


\section{REFERENSI}

1. Supartono, Basuki. Penyembuhan Pengapuran Sendi Lutut. Jakarta: Dewan Pengurus Nasional Bulan Sabit Merah Indonesia; 2016.

2. Koentjoro, S.L. Hubungan antara Indeks Masa Tubuh (IMT) dengan Derajat Osteoarthritis Lutut Menurut Kellgren dan Lawrence [Skripsi]. Semarang: Jurnal Kedokteran Universitas Diponegoro; 2017 [diakses tanggal 23 Agustus 2017]. Tersedia dari: eprints.undip.ac.id/23723/1/Sara_Listyani.pdf

3. Yusriati A. Pengaruh Kompres Hangat Rebusan Jahe (Zingiber Officinale) Terhadap Intensitas Nyeri Pada Penderita Osteoartritis Di Wilayah Kerja Puskesmas Andalas Padang [Skripsi]. Padang: Jurnal Kesehatan Andalas; 2016 [diakses tanggal 2 Agustus 2017]. Tersedia dari: http://scholar.unand.ac.id/16710/

4. Soenarto. Reumatik pada Usia Lanjut. Buku Ajar Boehi-Darmojo Geriatri (IImu Kesehatan Usia Lanjut). Edisi 4. Jakarta: Balai Penerbit FKUI; 2010. p. 433-7.

5. Supartono, Basuki. Regenerasi Tulang Rawan Hialin Pada Defek Osteokondral Melalui Penyuntikan Intraartrikular Suspensi Sel Punca CD34+ Darah Tepi Manusia, Asam Hialuronat, TGF-B1, IGF, FGF dan Fibronektin Pada Tikus Spraque Dawley [Disertasi]. Jakarta: Fakultas Kedokteran Program Studi Doktor IImu Kedokteran Universitas Indonesia; 2013.

6. Jacobson, Jon A. Fundamental of Musculoskeletal Ultrasound Edition 2. Philadelphia: Elsevier Saunders; 2013.

7. Mortada, Mohamed, Ayman Z., Mirvat A. E. A., Nillie E., M. Elgawish. Reliability of a Proposed Ultrasonographic Grading Scale for Severity of Primary Knee Osteoarthritis [Internet]. PubMed. 2016 [diakses tanggal 27 Desember 2017]. Tersedia dari: https://www.ncbi.nlm.nih.gov/pubmed/27478389

8. Kazam, J. K., Levon N., Theodore T., Carolyn M., Laurence P., Ronald S. Sonographic evaluation of femoral trochlear cartilage in patients with knee pain [Internet]. PubMed. 2011 [diakses tanggal 10 Januari 2018].Tersedia dari: https://www.ncbi.nlm.nih.gov/pubmed/21632994

9. Sastroasmoro, S. Dasar-dasar Metodologi Penelitian Klinis. Jakarta: Sagung Seto; 2011.

10. Heidari, Behzad. Knee Osteoarthritis Prevalence, Risk Factors, Pathogenesis, and Features: Part I [Internet]. PubMed. 2011 [diakses tanggal 21 Mei 2018]. Tersedia dari: https://www.ncbi.nlm.nih.gov/pmc/articles/PMC3766936/pdf/cjim-2-205.pdf

11. Hame, S.L., Alexander R.A. Knee Osteoarthritis In Women [Internet]. PubMed. 2013 [diakses tanggal 18 Juni 2018]. Tersedia dari: https://www.ncbi.n/m.nih.gov/pmc/articles/PMC3702776/

12. Mutiwara E., Najirman, Afriwardi. 2016. Hubungan Indeks Massa Tubuh dengan Derajat Kerusakan Sendi pada Pasien Osteoartritis Lutut di RSUP Dr. M. Djamil Padang [Skripsi]. Padang: Jurnal Kesehatan Andalas; 2016 [diakses tanggal 6 September 2017]. Tersedia dari: jurnal.fk.unand.ac.id/index.php/jka/article/view/525

13. Grassi W., Lamanna G., Farina A., Cervini C. Sonographic Imaging of Normal and Osteoarthritis Cartilage [Internet]. PubMed. 1999 [diakses tanggal 24 Mei 2018]. Tersedia dari: https://www.ncbi.nlm.nih.gov/pubmed/10406407 